\title{
Empathy in the emotional interactions with patients. Is it positive for nurses too?
}

\author{
Letizia Dal Santo ${ }^{1}$, Sabine PohI $^{2}$, Luisa Saiani ${ }^{3}$, Adalgisa Battistelli $^{4}$ \\ 1. Department of Nursing Sciences, University of Verona, Verona, Italy. 2. Work and Economic Psychology Lab, Université \\ Libre de Bruxelles, Brussels, Belgium. 3. Department of Public Health and Community Medicine, University of Verona, di \\ Verona, Italy. 4. EA4139 Psychology, Healthy and Quality of Life Lab, University of Bordeaux Segalen, Bordeaux, France.
}

Correspondence: Letizia Dal Santo. Address: Department of Nursing Sciences, University of Verona, viale San Lazzaro 21, 36100 Vicenza, Italy. Email: letizia.dalsanto@univr.it

Received: July 2, 2013

DOI : $10.5430 /$ jnep.v4n2p74
Accepted: August 20, $2013 \quad$ Online Published: September 29, 2013

URL: http://dx.doi.org/10.5430/jnep.v4n2p74

\section{Abstract}

Empathy, a complex and multidimensional concept, has been defined in many ways within the context of nursing. Although there is general support that nurses' empathic attitude is important for patient's adherence to treatment and care satisfaction, there are still some inconsistencies in the link between empathy and nurses' well-being. The general aim of this study is to verify the role played by empathy in promoting well-being in nursing work. Therefore, 222 nurses from different hospitals in a north region of Italy, completed a self-administered questionnaire. A cross-sectional survey was conducted.

Our result show that empathy is composed by two factors: a cognitive dimension (perspective taking) and an affective one (compassion). Perspective taking enhances job satisfaction, work engagement and reduces turnover intention. Compassion does not. These findings confirm that perspective taking and compassion have different impact on nurses' well-being. Further studies is required to inform education or for application in clinical settings.

\section{Key words}

Clinical empathy, Perspective taking, Compassionate care, Nursing, Work engagement

\section{Introduction}

In recent times, evidence has steadily accumulated in support of the utility of empathy in nursing ${ }^{[2]}$. The importance of empathy in the nursing context is related to a core of common aims and purposes ${ }^{[3]}$. There is general support that nurses' empathic attitude is important for patient's adherence to treatment. Empathy was also found to predict ratings of clinical competence and diagnostic accuracy ${ }^{[4,5]}$. Although there are general support and acceptation for the positive link between empathy, patients' outcomes and clinical competence, there are still some inconsistencies in the link between empathy and nurses' well-being ${ }^{[1]}$. For example there are controversial results about the correlations between empathy and burn out ${ }^{[6]}$ and empathy and working stress ${ }^{[7]}$. Some studies indicate possible associations between empathy and nurse's fatigue, hunger and depression ${ }^{[8]}$. On the other hand, Hochschild ${ }^{[9]}$ noted that empathy, in emotional interactions with patients, enhances nurses' job satisfaction. Pedersen ${ }^{[10]}$ suggests that these controversial results are found because empirical research on empathy is dominated by relatively quantitative methods and the concept of empathy has not been adequately 
explored. Although empathy is among the most mentioned dimension of patient care, there are still ambiguities associated with this concept ${ }^{[11]}$. The aim of this paper is twofold. First, we want to clarify the concept of empathy and test its structure. Second, we aim to verify the role played by empathy in promoting well-being in nursing work.

\subsection{Empathy}

The notion of "empathy" has a long history marked by ambiguity, discrepancy and controversy among philosophers, behavioral, social, and medical scholars ${ }^{[12-14]}$. Empathy has been conceptualized as an "elusive" concept ${ }^{[15]}$ difficult to define and measure ${ }^{[16]}$. There is general agreement in defining empathy as a mode of relating in which one person comes to know the mental content of another, both emotionally and cognitively, at a particular moment in time. Cognition is mental activities involved in acquiring and processing information for better understanding, whereas emotion is sharing of the affect manifested in subjectively experienced feelings. Empathy can be described as a cognitive or an emotional attribute or a combination of both. Recent studies described empathy as the neural matching mechanism constituted of a mirror neuron system in the brain, which enables to place oneself in the "mental shoes" of others. Moreover, empathy in humans is assisted by other abstract and domain-general high-level cognitive abilities such as executive functions and language, as well as the ability to differentiate another's mental states from one's own, which expand the range of behaviors that can be driven by empathy ${ }^{[17,18]}$. These evidences suggest that cognition is a fundamental component of empathy and this characteristic differentiates empathy from other forms of emotional sharing such as emotional contagion, affective identification and sympathy. Cognitive empathy refers to one person's attempt to comprehend non judgmentally another person's experiences ${ }^{[14]}$. According to these studies, Hojat ${ }^{[11]}$ started to conceptualize empathy by distinguishing it from sympathy. Empathy is in the area of higher cognition than emotion. Conversely, sympathy is in the area of higher emotion than cognition. Compassion, resides in the area of the overlap between empathy and sympathy. In clinical settings, as nursing, empathy involves an effort to understand the patient's experiences without joining them, whereas sympathy involves a feeling of sharing or joining the patient's pain and suffering ${ }^{[12]}$. The distinction between sympathy and empathy is not only a theoretical quarrel, but has important implications for the nurse-patient relationship. When a nurse joins the patient's emotions (a key feature of sympathy), clinical outcomes are impeded. A nurse should feel the patient's feelings only to a limited extent to improve his or her understanding of the patient without impeding professional judgment ${ }^{[19]}$. The cognitive filter of empathy allows individuals to disentangle themselves from others, whereas individuals experiencing sympathy have difficulty maintaining a sense of whose feelings belong to whom ${ }^{[17]}$. An "emotional distance" between nurse and patient is desirable not only to avoid an intense emotional involvement, which can jeopardize the principle of clinical neutrality, but also to maintain nurses' personal durability ${ }^{[20]}$. According to these studies, we assume that empathy is a positive emotional competence which may help nurses in handling emotional interactions with patients and in promoting well-being experiences at work.

\subsection{Work engagement, job satisfaction and nurses' turnover intention as well-being indicators}

Work engagement can be defined as a persistent, pervasive and positive affective-motivational state of fulfilment in employees ${ }^{[21]}$. Engaged employees find their work to be meaningful and in line with their values. According to Maslach and Leiter ${ }^{[22]}$, employees achieve their best when they believe in what they are doing. Recent papers have called for more research on this construct to be conducted with nurses because nurses' engagement is still inadequately understood $^{[23]}$. Interventions aimed at fostering engagement are called for. Through future research in the area of engagement, it is believed that nurses will gain more positive experiences from their work and subsequently a greater sense of wellbeing ${ }^{[24]}$. Nurses' engagement appears to center on intrinsic reward and connection with others ${ }^{[25]}$. Involvement with patients plays a key role in fostering nurses' engagement ${ }^{[23]}$. Mackintosh ${ }^{[26]}$ claims that the development of a successful relationship with patients builds the work related persona as separate from the individual own persona and that enabled nurses to continue to work successfully in what otherwise might be considered a high stress situation. We hypothesize that empathy with its cognitive filter allows nurses to maintain a good distance with the patient and is positively linked to work engagement. 


\section{Hypothesis 1: Empathy is positively related to work engagement}

Job satisfaction among nurses has been identified as a key factor in nurses' turnover with the empirical literature suggesting that it is related to a number of organizational, professional and personal variables ${ }^{[27]}$ and can be defined as a quality outcome indicator ${ }^{[28]}$. Job satisfaction has been described as an individual attitude to how well personal expectations at work correspond to outcomes. Theodosius ${ }^{[29]}$ considers managing emotions in interactions with patients as essential elements in fulfilling nurses' expectations. Nurses consider the relation with patient as a key element in the perception of being a "good nurse" ${ }^{[30]}$. Hochschild ${ }^{[9]}$ found that when nurses are able to handle inner feelings and manage with patients' emotions, job satisfaction is enhanced. In regard to that, Perry ${ }^{[31]}$ found that nurses who have provided high quality care and have made emotional connections with patients feel very satisfied with their professional work life. We aim to test the role played by empathy in connection with patients and we hypothesize that empathy is positively correlated with job satisfaction

\section{Hypothesis 2: Empathy is positively related to job satisfaction}

Jones ${ }^{[32]}$ defined nursing turnover as the process whereby nursing staff leave or transfer within the hospital environment. This definition encompasses voluntary and involuntary, as well as internal and external turnovers. High nurses' turnover can impact negatively on an organization's capacity to meet patient needs and provide quality care ${ }^{[33]}$. At the nursing unit level, high turnover affects the morale of nurses and the productivity of those who remain to provide care ${ }^{[34]}$. Ongoing workforce instability in many countries is raising questions about the impact of nurse turnover on the well-being of nurses, quality of patient care and system costs. Recently, considerable attention has been committed to understanding organizational, individual and economic factors that influence turnover behavior ${ }^{[35]}$. A special attention was given to workload ${ }^{[34]}$. A consistently heavy workload was found to increase job tension and decreases job satisfactions, which in turn, increase the likelihood of turnover ${ }^{[36]}$. Empirical evidence suggests that each additional patient per nurse is associated with a $23 \%$ increase in burnout and a $15 \%$ increase in the odds of job dissatisfaction ${ }^{[37]}$. O'Brien Pallas ${ }^{[38]}$ had emphasized that workload measurement should focus on the complexity of the patient situation rather than on the actual tasks.

More in detail, Hochschild ${ }^{[9]}$ pointed that a significant element of nursing workload is the high emotional labor spent in relationship with patient. The author categorizes different emotional regulation strategies used by nurses in relation with patient. These strategies are divided in functional and dysfunctional in regard to nurses' well-being. We assume that empathy is a functional strategy which helps nurses to handle with emotional workload and contributes to reduce turnover intention.

\section{Hypothesis 3: Empathy is positively related to turnover}

\section{Method}

\subsection{Participants and procedures}

A cross-sectional survey was conducted. A convenience sample of registered nurses was recruited for this study. For the recruitment of the sample, hospitals within the public sector and that were in urban areas were used. After contacting the hospitals, the nurses for whom the administration gave formal approval to participate were contacted and recruited. In total, this research involved 300 registered nurses from different hospitals in a north region of Italy.

Of the 300 copies distributed, 222 were answered, for an overall response rate of $74 \%$. The data were collected by using a paper questionnaire, which was distributed to the nurses through the nurse supervisor of each unit. The participants anonymously and voluntarily completed the questionnaire during working hours. Nurses were given 3 weeks to complete and return their questionnaire in locked boxes.

The survey was anonymous but participants were asked to provide information on their gender, age, level of professional rank and service. The sample was $78.6 \%$ women and $21.4 \%$ men. Mean of age is 38.44 years and mean of professional tenure is 16.2 years. 


\subsection{Measures}

Empathy: the Jefferson Scale of Physician Empathy translated and validated into Italian by Di Lillo et al. was used ${ }^{[39]}$. The HP (health professional) version of the scale was used and slightly modified in order to best fit to nursing sample. This scale encompasses two components of empathy, perspective taking and compassion. It contains 12 items each answered on a 5 point likert scale. To reduce acquiescence response style some items are negatively worded and reversed scored. A higher score denotes a higher level of empathy. Sample item included: "My patients feel better when I understand their feelings.”

Work engagement: was measured using the Italian validated version of UWES-9 (Utrecht Work Engagement Scale) ${ }^{[40]}$. UWES-9 contains 9 items. Each item is answered on a 5 point scale. Sample item included: "I'm full of energy while I'm working."

Job satisfaction: The adapted Italian version of the Index of Work Satisfaction ${ }^{[41]}$. It's a self report scale with 22 items which investigate different element of nurses' job satisfaction: for contents and for relationship with colleagues and supervisor. Each item is answered on a 5 point scale. Sample item included: "I'm satisfied for the sense of fulfilment generated in my job”.

Turnover intention: Turnover intention was measured by two items on a five point likert scale ${ }^{[35]}$. The sample item included "I am going to seek another job next year."

\subsection{Ethical considerations}

The study was approved by the ethical committee of the University of Brussels, in accordance with the Code of Ethics of the World Medical Association (Declaration of Helsinki). The participants were informed that their anonymity was assured. Informed consent to participate was assumed when the nurses returned a completed questionnaire.

\section{Results}

\subsection{Measurement model of empathy}

A confirmatory analysis was performed to verify the factorial structure of empathy. Results are reported in table 1. Confirmatory factorial analysis was performed using EQS. Results show the two factors solution has good fit index $\left(x^{2} 0\right.$ 126.3 $\mathrm{df}=63$, RMSEA (Root Mean Square Error of Approximation) $=0.07$, CFI (Comparative fit index) $=0.93$, GFI (Good Fit Index $)=0.92)$. This factorial structure confirms the two components of empathy proposed by Hojat (2007): perspective taking (PT) and compassion (COMP). PT and COMP's correlations are reported in table2.Regression analyses are also conducted in order to address our hypotheses. The analyses were carried out by using SPSS software program, version 17.0.

Table 3 shows regressions' analysis results among predictors and the outcomes considered in this study.

\subsection{Analysis of hypotheses}

Hypothesis 1 predicted that empathy would be positively related to work engagement. As seen in table 3, the cognitive component of empathy was significantly and positively related to work engagement, but the affective component of empathy was not significantly related to work engagement. Thus, Hypothesis 1 was partially supported.

Hypothesis 2 proposed that empathy would be positively linked to job satisfaction. As we can see in Table 3, only is perspective taking positively associate to job satisfaction. Hypothesis 2 was also partially supported.

Hypothesis 3 proposed that empathy would be positively related to turn-over. Only perspective taking is negatively associate to turn-over. Hypothesis 3 was also partially supported. 
Table 1. Empathy's Confirmatory Factor Analysis

\begin{tabular}{lll}
\hline Items & $\mathbf{2}$ \\
\hline My patients feel better when I understand their feelings & .734 \\
I try to understand what is going on in my patients' minds by paying attention to their non verbal cues and body & .721 \\
language. & .703 \\
My understanding of how my patients and their families feel does not influence medical or surgical treatment & .685 \\
I try to imagine myself in my patients' shoes when providing care to them & .679 \\
I consider asking patients about what is happening in their lives as an important factor in understanding their & .671 \\
complaints & .564 \\
I try to think like my patient in order to render better care & .724 \\
Empathy is a therapeutic skill without which my success as a nurse would be limited & .709 \\
Affections to my patients have significant place in caring & .685 \\
Emotional ties with my patients have significant influence on their healing outcomes \\
Attentiveness to my patients' personal experience is irrelevant to treatment effectiveness \\
I try not to pay attention to my patients emotions in interviewing and history taking \\
How my patients feel is a relevant factor in medical treatment \\
\hline
\end{tabular}

Table 2. Means, Standard Deviations and Correlation (Cronbach's alphas are shown in italics)

\begin{tabular}{llllllll}
\hline & Means & SD & PT & COMP & EMP & JS & TUR \\
\hline PT & 3.87 & .98 & .87 & & & & \\
COMP & 3.72 & .97 & $.409^{* *}$ & .74 & & & \\
JS & 3.55 & .60 & $.377^{* *}$ & $.188^{*}$ & $.361^{* *}$ & .72 & .93 \\
TUR & 3.94 & .72 & $-.231^{* *}$ & -.085 & $-.208^{* *}$ & $-.198^{* *}$ & .93 \\
WE & 3.34 & .98 & $.385^{* *}$ & $.165^{*}$ & $.362^{* *}$ & $.334^{* *}$ & $-.334^{* *}$ \\
\hline
\end{tabular}

Note. $\mathrm{N}=222 * p<.05$ (two tailed) ${ }^{* *} p<.01$ (two tailed)., $\mathrm{PT}=$ Perspective Taking; COMP = Compassionate Care, JS = Job Satisfaction, TUR $=$ Turnover intention, $\mathrm{WE}=$ Work Engagement

Table 3. Linear Regression Analysis

\begin{tabular}{llllllllll}
\hline \multirow{2}{*}{ Predictors } & \multicolumn{4}{c}{ JS } & \multicolumn{4}{c}{ WE } & \multicolumn{2}{c}{ TUR } \\
\cline { 2 - 10 } & T & Beta & Sig & T & Beta & Sig & T & Beta & Sig \\
\hline PT & 6,00 & .387 & .000 & 5.48 & .376 & .000 & 5.22 & .361 & .000 \\
COMP & -1.03 & -.075 & .303 & 3.35 & .023 & .738 & .557 & .041 & .558 \\
Adj R & & .148 & & & .150 & & & .114 & \\
\hline
\end{tabular}

Note. $\mathrm{PT}=$ Perspective Taking; COMP = Compassionate Care, WE = work Engagement, JS = Job Satisfaction, TUR = Turnover intention

\section{Discussions}

Our results confirm previous observations which claim that the two components of empathy should be distinguished in order to better understand its nature ${ }^{[11]}$. The cognitive core of empathy (perspective taking), is positively related to work engagement, job satisfaction and negatively to turn over intention, whereas compassion does not. The cognitive filter of empathy enables individuals to disentangle themselves from other's feelings and maintain a sense of whose feelings belong to whom. The cognitive domain of empathy involves the ability to understand another person's inner experience and to view the ${ }^{[17]}$ outside world from the other's person's perspective ${ }^{[11]}$. Individuals perform perspective taking to generate emotions and responses appropriate to the situation ${ }^{[42]}$. The affective component involves the capacity to enter into and join the feelings of another person ${ }^{[12]}$. Therefore compassion leads individuals to put forth more effort to preserve their personal space. Compassionate care, if excessive and not mediated, could interfere with objectivity in diagnosis and treatment ${ }^{[12]}$ and could burst of emotions that might interfere with personal durability ${ }^{[20]}$. The results confirm the "detached attachment” produced by perspective taking makes empathy as a useful competence for nursing professsion ${ }^{[43]}$.When nurses respond with empathetic perspective taking, their feelings are not aroused, nor do they parallel those 
of patients. Nurses "feel for" patients, but not "feel with" them ${ }^{[44]}$. This kind of emotional sharing has some relevant implications. When nurses successfully manage emotions in interaction with patients they are more satisfied and engaged with their work.

This result is consistent with Mackintosh's study ${ }^{[26]}$. The author claims that the development of a successful relationship with patients builds the work related persona as separate from the individuals own persona and that enabled nurses to engage to work successfully.

The composite nature of empathy becomes clear in Carl Rogers definition: "the ability to sense the patient's private world as if it were your own, but without losing the "as if" quality ${ }^{[45]}$. The conceptualization of empathy as a capability to combine affective and cognitive elements confutes the social representations of nurses as "good samaritans", devoted to their patients. Motivation for empathetic health care relations is not a question of missionary intents, but a result of emotional exchange and lead to develop an internal working model as well as to the regulation of emotions, both of which function as guides to interpersonal relationships ${ }^{[46]}$.

\section{Conclusion}

Future researches have to better understand how health education system and organizational policies could better foster, value and enhance empathy among employees. In the nursing contest this seems moreover important because interactions with patients play a significant role in the emotional workload ${ }^{[47]}$. Nursing student and registered nurses would benefit from being taught and informed about the appropriate emotional strategies to protect their own well-being and the well-being of patients and to achieve organizational outcomes. Despite the consensus regarding the importance of an empathetic caring, insufficient attention has been given to enhancement of the capacity for empathy in the design of nursing education curriculum. Hunter and Smith ${ }^{[48]}$ show nursing students feel unable to dealing with the emotional demands of practice and suggest that the lack of education and information about the potential exploiting power of emotion may contribute to the actual nurses' crisis. These findings suggest emotional strategies need to be countered by education and training and informed by research. Empathy has to be trained and valued especially in those situations where interactions with patients are prolonged and difficult (psychiatry, oncology, geriatrics, pediatrics...) and may lead nurses to emotional exhaustion, stress and, in a long term, to burn out and intentions to quit. Future researches should also investigate both personal and organizational antecedents of empathy. It seems important to test how supervisor and health organisation may support nurses in handling with the emotional workload with patients. It was found that supervisor's and organizational support plays an important role in taking into account nurses' work-related needs and supporting them to perform better in their own work ${ }^{[35]}$. Better investigation on empathy could help to highlight the invisible emotional workload of nursing and this recognition could foster the quality of caring and promote nurses' well-being. A program to address these issues must by necessity be ambitious and multifaceted and embrace education, research and practice. The educational aspect requires the incorporation of emotions into the nursing curriculum ${ }^{[49]}$ while the development of a research may seek to understand the nurse education and practice in order to close the theory-practice gap and inform nurse leaders and managers how best to support these endeavors.

\section{Limitations}

This study has several limitations, which might be addressed through further research. First, the use of self-reporting measures could raise doubts about the validity of the obtained data ${ }^{[50]}$. Future researches should consider the assessment in others points of view (supervisors, patients, etc....) to avoid potential problems related to common method bias. Second, a sample of nurses from the north Italy was used. Therefore, it is impossible to compare the measures of this study with data from other regions of Italy. In order to obtain greater support for the model, it might be necessary to replicate the study with nurses from different geographic areas of Italy (e.g. nurses in central and southern areas). Furthermore, the impossibility of comparing measures analyzed with data obtained in different organizational environments and with different types of employees also reduces the external validity of the research. To obtain greater support for the model, it might be 
necessary to enlarge the study with different populations of workers. Another limitation is the lack of experimental and longitudinal design. Because of the design chosen for this study, the difficulty of inferring causality entails a significant limitation. Duplication of this study using a longitudinal design should serve to mitigate this limitation. Future studies necessarily should consider such a method, and test long-term effects on the relationships examined in the present study and the outcomes.

\section{Acknowledgments}

A special thank to prof. Hojat for his cooperation and Maura Galletta for her good pieces of advice. The authors also thank all nurses who participated to this research.

\section{References}

[1] Yu, J. \&Kirk, M. Measurement of empathy in nursing research: systematic review. Journal of Advanced Nursing. 2008; 64(5): 440-454.PMid:19146512 http://dx.doi.org/10.1111/j.1365-2648.2008.04831.x

[2] Mercer, S., \& Reynolds, T. Empathy and quality of care. British Journal of General Practice. 2002; 2: 9-13.

[3] Branch, W.T. Teaching the human dimension of care in clinical settings. JAMA. 2001; 286: 1067-1074.PMid:11559292 http://dx.doi.org/10.1001/jama.286.9.1067

[4] Sayumporn, W., Gallagher, S., Brown, P., Evans, J., Flynn, V., \& Lopez, V. The perception of nurses in their management of patients experiencing anxiety. Journal of Nursing Education and Practice. 2012; 2(3): 25-45. http://dx.doi.org/10.5430/jnep.v2n3p38

[5] Veloski, J., \&Hojat, M. Measuring specific elements of professionalism: empathy, teamwork and lifelong learning. Oxford: Oxford University Press, 2006. PMCid:PMC1831612

[6] Aström, S., Nilsson,M., Norberg, A, Winblad, B.Empathy, experience of burnout and attitudes towards demented patients among nursing staff in geriatric care. Journal of Advanced Nursing. 1990; 15: 1236-44. PMid:2269745 http://dx.doi.org/10.1111/j.1365-2648.1990.tb01738.x

[7] Beddoe, A.E., Murphy, P. Does mindfulness decrease stress and foster empathy among nurses? Journal of Nursing Education. 2004; 43: 305-312. PMid:15303583

[8] Thomas, K. Cognitive element of empowerment. Academy of Management Review.1996; 15: 666-681.

[9] Hochschild, A. R. The Managed Heart: Commercialization of Human Feeling. Berkeley: University of California Press, 1983. PMid:6218886

[10] Pedersen, R.Empirical research on empathy in medicine - A critical review. Patient Education and Counseling. 2009; 76(3): 307-322. PMid:19631488http://dx.doi.org/10.1016/j.pec.2009.06.012

[11] Hojat, M. Empathy in patient care: Antecedents, development, measurement and outcomes. New York: Springer, 2007.

[12] Aring, C., D. Sympathy and empathy.Journal of the American Medical Association. 1958; 167: 448-452. http://dx.doi.org/10.1001/jama.1958.02990210034008

[13] Preston, S. D., \&deWaal, F. B. M. Empathy: It’s ultimate and proximate bases. Behavioral and Brain Sciences. 2002; 25: 1-20. PMid:12625087

[14] Wispé, L. Altruism, sympathy, and helping: Psychological and sociological principles. New York: Academic Press, 1978.

[15] Basch, M. F. Empathic understanding: A review of the concept and some theoretical considerations. Journal of the American Psychoanalytic Association. 1983; 31: 101-126. http://dx.doi.org/10.1177/000306518303100104

[16] Kestenbaum, R. Individual differences in empathy among pre-scholars. In Eisenberg, N. Empathy and related emotional responses (pp. 51-64). San Francisco: Jossey-Bass, 1989. PMid:2771129

[17] Decety, J., \& Jackson, P. L. A social-neuroscience perspective on empathy.Current Directions in Psychological Science. $2006 ; 15:$ 54-58. http://dx.doi.org/10.1111/j.0963-7214.2006.00406.x

[18] Gallese, V. The roots of empathy. Psychopathology. 2003; 36, 171-180. PMid:14504450http://dx.doi.org/10.1159/000072786

[19] Starcevic, V., \&Piontek, C. Empathic understanding revisited: Conceptualization, controversies, and limitations. American Journal of Psychotherapy. 1997; 51: 317-328. PMid:9327101

[20] Jensen, N. The empathic physician. Archives of Internal Medicine. 1994; 154: 108-121. http://dx.doi.org/10.1001/archinte.1994.00420010142017

[21] Schaufeli, W., Salanova, M., Gonzalez-Roma, V., \& Bakker, A.B. The measurement of engagement and burnout: A two sample confirmatory factor analytic approach. Journal of Happiness Studies. 2002; 3; 71-92. http://dx.doi.org/10.1023/A:1015630930326

[22] Maslach, C., \&Leiter, M., P. The truth about burnout. San Francisco, CA: Jossey-Bass, 1997.

[23] Freeney, Y, \&Tiernan, J. Exploration of the facilitators of and barriers to work engagement in nursing.International Journal of Nursing Studies. 2009; 46(12): 1557-1565. PMid:19523629 http://dx.doi.org/10.1016/j.ijnurstu.2009.05.003 
[24] Landau, K. Psycho-physical strain and the burn-out phenomenon amongst health care professionals. In M. Estryn-Behar, C. Gadbois, \& M. Pottier (Eds.), Ergonomie à l’hopital (pp.77-88) International symposium Paris, Editions Octares, Toulouse, 1992.

[25] Simpson, M. Engagement at work: a review of the literature. International Journal of Nursing Studies. 2008; 43: 521-534.

[26] Mackintosh, C. Protecting the self: A descriptive qualitative exploration of how registered nurses cope with working in surgical areas. International Journal of Nursing Studies. 2007; 44: 982-990. PMid:16793044 http://dx.doi.org/10.1016/j.ijnurstu.2006.04.009

[27] Portoghese, I., Galletta, M. \& Battistelli, A. The Effects of Work-Family Conflict and Community Embeddedness on Employee Satisfaction: The Role of Leader-Member Exchange. Business and Management. 2011; 6(4): 32-48.

[28] Lu, A., Alison, E., \&Barriball, L. Job satisfaction among nurses: a review of the literature. International Journal of Nursing Studies. 2005; 42: 211-247. PMid:15680619 http://dx.doi.org/10.1016/j.ijnurstu.2004.09.003

[29] Theodosius, C. Emotional labour in health care: The unmanaged heart of nursing. Hoboken: Taylor \& Francis, 2008.

[30] Gregg, M., F., \&Magilvy, J., K. Values in clinical nursing practice and caring. Japan Journal of Nursing Science. 2004; (1): 11-18. http://dx.doi.org/10.1111/j.1742-7924.2004.00005.x

[31] Perry, L. Choosing nursing: becoming, staying, flourishing. Journal of Advanced Nursing. 2012; 68: 1441-1442. PMid:22712896 http://dx.doi.org/10.1111/j.1365-2648.2012.06074.x

[32] Jones, C.B., Staff nurse turnover costs: Part I, a conceptual model. Journal of Nursing Administration. 1990; 20(4): 18-23. PMid:2109052 http://dx.doi.org/10.1097/00005110-199004000-00005

[33] Shields, M.A., \&Ward, M., Improving nurse retention in the National Health Service in England: the impact of job satisfaction on intentions to quit. Journal of Health Economics. 2001; 20(5): 677-701. http://dx.doi.org/10.1016/S0167-6296(01)00092-3

[34] Hayes, L. Nurse Turnover. A literally review. International Journal of Nursing Studies. 2006; 43: 237-263. PMid:15878771 http://dx.doi.org/10.1016/j.ijnurstu.2005.02.007

[35] Galletta, M., Portoghese, I., Penna, M.P., Battistelli, A., \&Saiani, L. Turn over intention among Italian nurses: the moderation roles of supervisor support and organizational support. Nursing and Health Sciences. 2011; 13: 184-191. PMid:21595810 http://dx.doi.org/10.1111/j.1442-2018.2011.00596.x

[36] Strachota, E., Normandin, P., O’Brien, N., Clary, M., \&Krukow, B. Reasons registered nurses leave or change employment status. Journal of Nursing Administration. 2003; 33(2): 111-117. http://dx.doi.org/10.1097/00005110-200302000-00008

[37] Aiken, L.H., \& Patrician, P. A. Measuring organizational traits of hospitals: the revised nursing work index. Nursing Research. 2000; 49(3): 146-153. http://dx.doi.org/10.1097/00006199-200005000-00006

[38] O’Brien Pallas, L. The Impact of Nurse Turnover on Patient, Nurse, and System Outcomes: A Pilot Study and Focus for a Multicenter International Study. Policy Politics Nursing Practice. 2006; 7: 169-179. PMid:17071704 http://dx.doi.org/10.1177/1527154406291936

[39] Di Lillo, M., Cicchetti, A., Lo Scalzo, A.,Taroni, F., \&Hojat, M. The Jefferson Scale of Empathy: Preliminary Psychometrics and Group Comparisons in Italian Pysicians Academic Medecine. 2009; 1(9): 1198-1102. PMid:19707057 http://dx.doi.org/10.1097/ACM.0b013e3181b17b3f

[40] Balducci, C., Schaufeli, W., \&Fraccaroli, F. Psychometric properties of the Utrecht Work Engagement Scale.European Journal of Psychological Assessment. 2010; 26(2): 143-149. http://dx.doi.org/10.1027/1015-5759/a000020

[41] Stamps, P.L., \&Piedmonte, E.B. Nurses and Work Satisfaction: An Index for Measurement. Health Administrative.Journal of Advanced Nursing. 1986; 27: 355-363.

[42] Chu, K.H., Baker, M.A. \&Murrmann, S.K. When we are onstage, we smile: the effects of emotional labor on employee work outcomes. International Journal of Hospitality Management. 2011; 3: 67-95.

[43] Alligood, M.R. Rethinking empathy in nursing education: shifting to a developmental view. Annual Review of Nursing Education. 2005; 3: 299-309.

[44] Kruml, S.M. \& Geddes, D. Exploring the dimensions of emotional labor. Management Communication Quarterly. 2000 ; 1(14): 8-49. http://dx.doi.org/10.1177/0893318900141002

[45] Rogers, C. R. Empathic: An unappreciated way of being. Counseling Psychologist. 1975; 5: 2-11. http://dx.doi.org/10.1177/001100007500500202

[46] Eisenberg, N. Empathy and related emotional responses (Vol. 44). San Francisco: Jossey-Bass, 1989.

[47] Mann, S. A health-care model of emotional labour. Journal of Health Organization and Management. 2005; 19; 304-317. http://dx.doi.org/10.1108/14777260510615369

[48] Hunter, A., \& Smith, R. Emotional labour: just another buzz word? International Journal of Nursing Studies. 2007 ; 44; 859-861. PMid:17367794 http://dx.doi.org/10.1016/j.ijnurstu.2006.12.015

[49] Smith, P., \&Allan, E. "We should be able to bear our patients in our teaching in some way”: Theoretical perspectives on how nurse teachers manage their emotions to negotiate the split between education and caring practice. Nurse Education Today. 2010; 30: 218-223. PMid:20089333 http://dx.doi.org/10.1016/j.nedt.2009.12.015

[50] Goffin, R. A multi-rater assessment of organizational commitment: are self reported measures biased? Journal of organizational behavior. 2001; 22: 437-451. http://dx.doi.org/10.1002/job.94 